Etnográfica

Revista do Centro em Rede de Investigação em

Antropologia

vol. $15(1) \mid 2011$

Vol. $15(1)$

\title{
Polícia e violência urbana em uma cidade brasileira
}

Reconstruct police or society? Violence, democracy and public order in

contemporary Rio de Janeiro

\section{Luiz Antonio Machado da Silva}

\section{(2) OpenEdition \\ Journals}

Edição electrónica

URL: https://journals.openedition.org/etnografica/828

DOI: $10.4000 /$ etnografica. 828

ISSN: 2182-2891

Editora

Centro em Rede de Investigação em Antropologia

\section{Edição impressa}

Data de publição: 1 fevereiro 2011

Paginação: 67-82

ISSN: 0873-6561

\section{Refêrencia eletrónica}

Luiz Antonio Machado da Silva, «Polícia e violência urbana em uma cidade brasileira», Etnográfica [Online], vol. 15 (1) | 2011, posto online no dia 26 outubro 2011, consultado o 11 fevereiro 2022. URL: http://journals.openedition.org/etnografica/828 ; DOI: https://doi.org/10.4000/etnografica.828

\section{(c) (1) \&}

Etnográfica is licensed under a Creative Commons Attribution-NonCommercial 4.0 International License. 


\title{
Polícia e violência urbana em uma cidade brasileira
}

\section{Luiz Antonio Machado da Silva}

\begin{abstract}
O trabalho discute questões relacionadas à expansão da violência criminal no Rio de Janeiro. Parte-se da hipótese de que a noção prática de "violência urbana" é o centro de uma "província de significado" embutida na linguagem de senso comum, que capta e confere sentido a uma forma de vida autônoma, a sociabilidade violenta. A "violência urbana" tematiza as ameaças à continuidade das rotinas cotidianas, alterando a compreensão do significado do controle social e delegando na polícia a preservação das rotinas a qualquer custo. Dessa maneira, favorece a manutenção da polícia como uma instituição pré-moderna, talvez a única com esta característica no Brasil de hoje, e torna inócuas as inúmeras propostas de intervenção técnico-administrativa e moral que visam "refundá-la".

PALAVRAS-CHAVE: Rio de Janeiro, violência urbana, tráfico de drogas, ordem pública, sociabilidade, segregação social.
\end{abstract}

\section{O PROBLEMA}

Neste artigo, proponho uma aproximação às questões relacionadas ao debate sobre a expansão da violência criminal nas grandes cidades brasileiras, com particular referência ao lugar e ao papel desempenhado pela atividade policial na discussão. Boa parte da polêmica tem caráter geral, porém o material empírico no qual me baseio refere-se a uma pesquisa que coordenei, realizada no Rio de Janeiro.

A investigação constou de um acompanhamento de inspiração etnográfica durante cerca de oito meses em três favelas (uma na zona norte da cidade, com longa tradição de luta política e atualmente com forte presença, ostensiva e armada, do tráfico de drogas; uma na zona sul, considerada "tranquila" pela ausência, ao menos ostensiva, do tráfico, o que também evita as incursões policiais que são muito comuns nos territórios da pobreza; e uma na zona oeste, dominada por um dos grupos paramilitares denominados "milícias", que se apresentam como opositores dos bandos de traficantes, e são constituídos 
principalmente por policiais, bombeiros, agentes penitenciários, que atuam com apoio informal das corporações policiais). Paralelamente, com base em laços prévios de confiança com os pesquisadores, foram recrutados cerca de 150 moradores de 50 favelas do município do Rio de Janeiro. ${ }^{1}$ Com eles, foram realizados 15 grupos focais, com duração aproximada de três horas cada um. Os primeiros resultados da pesquisa encontram-se em Machado da Silva (2008a). ${ }^{2}$

A inspiração para o presente trabalho surgiu da leitura de um artigo jornalístico de um pesquisador e político com importante intervenção no referido debate, intitulado "Refundar as polícias" (Soares 2009). No Brasil, a atividade policial é matéria da constituição federal, embora o combate ao crime comum seja da competência dos estados-membros, e está dividida entre uma Polícia Militar, encarregada do patrulhamento ostensivo, e uma Polícia Civil, encarregada da investigação criminal. Na prática, há muita tensão e superposição entre elas, sendo que a atuação da Polícia Militar tem mais visibilidade pública. No espaço deste artigo não é possível detalhar estas questões, de modo que falo da atividade policial em geral.

Em resumo, o texto de Soares toma posição a favor da desconstitucionalização da atividade policial, cuja organização ficaria a cargo de cada estado, e da criação de polícias estaduais "de ciclo completo", isto é, uma única organização ficaria encarregada da prevenção, repressão e investigação.

Deixando de lado um certo voluntarismo identificável pela ausência de indicações sobre que ator ou força social seria capaz de implementá-las, de minha parte considero inteiramente pertinentes ambas as propostas. Meu ponto não é a respeito da substância do artigo, mas restringe-se ao título, que considero uma excelente síntese das tendências dominantes na polêmica sobre a relação entre violência criminal e polícia, elemento central na agenda pública contemporânea nas cidades brasileiras. De fato, a metáfora da "refundação" resume a orientação básica de um grande número de propostas, com variáveis graus de sofisticação teórica e fundamentação empírica, que visam reduzir as manifestações de violência. As sugestões não são idênticas, mas todas adotam um pacote interpretativo ${ }^{3}$ por meio do qual a atividade criminal é explicada pelo

I Estima-se que a cidade tenha cerca de 850 áreas formalmente reconhecidas como favelas, que abrigam uma população de cerca de 15\% do total de moradores da cidade. (As estatísticas são imprecisas devido às dificuldades operacionais de aplicação da definição oficial dos "aglomerados subnormais".)

2 Agradeço a contribuição dos participantes do coletivo que realizou a pesquisa: Márcia Pereira Leite, Luis Carlos Fridman, Jussara Freire, Juliana Farias, Lia de Mattos Rocha, Wânia Mesquita e Pedro Paulo Oliveira. Devo dizer que sou incapaz de decidir quem é o "verdadeiro" autor de cada uma das observações que farei, uma vez que o grupo de pesquisa, apesar de intelectualmente bastante variado, trabalhou de modo muito coeso. Os erros, é claro, são de minha responsabilidade.

3 Para uma discussão da noção de pacote interpretativo no construtivismo americano, ver a primeira parte do trabalho de Fuks (1997). 
baixo custo de oportunidade dos desvios de conduta, consequência da corrupção e ineficiência policial. Desse modo, as sugestões convergem para tentativas de implementar, através de meios técnico-administrativos e jurídicos, uma "reforma intelectual e moral" das polícias, para recorrer à expressão de Gramsci. Nesta linha há uma ampla variedade de propostas, seja de pesquisadores, administradores ou políticos, seja de membros das próprias corporações policiais, os quais costumam se apresentar como uma espécie de "intelectuais orgânicos" (alguns acabam por entrar na política partidária, com variáveis graus de sucesso) mais qualificados, por sua experiência prática, do que os "de fora", tidos como preconceituosos.

O ponto de vista que pretendo desenvolver neste artigo é que o esgarçamento do tecido social nas cidades brasileiras está se tornando tão crítico que a metáfora da refundação, de fato, faz sentido. No entanto, estou convencido de que não é a polícia que deve ser "refundada", e sim a sociedade. Isto é, o que precisa ser mudado são os padrões concretos que organizam a sociabilidade urbana e a autoimagem que eles geram e da qual dependem. É desnecessário chamar a atenção para o fato de que, uma vez que a vida social é um fluxo sem começo nem fim, o uso da ideia de "refundação" é estritamente metafórico, servindo apenas para indicar a urgência e profundidade do problema.

Dito isso, é relevante acrescentar que o presente trabalho, ademais de ser uma descrição crítica do debate contemporâneo sobre a organização da sociabilidade nas cidades brasileiras influenciada pelo crime violento, é também uma tomada de posição.

Na próxima seção, esquematizo um pequeno conjunto de hipóteses sobre a forma como está organizado, na atualidade, o debate sobre a relação entre crime violento e polícia. Em seguida, discuto algumas características da atividade policial, tendo em vista, em particular, a questão da "refundação". $\mathrm{E}$, ao final, retomo algumas implicações esparsamente comentadas ao longo do texto. Especificamente, sugiro que a transformação operada pelo par "violência urbana"/sociabilidade violenta (ver adiante) na compreensão dos requisitos de controle social acabou por estabelecer uma oposição entre a linguagem que organiza as relações sociais a respeito da violência criminal e a linguagem dos direitos. A ideia de refundação, assim, deveria implicar um esforço no sentido de reincorporar o tratamento da relação entre crime violento e polícia no debate mais amplo sobre a expansão da democracia.

\section{O DEBATE PÚBLICO: BREVE ESQUEMA DESCRITIVO}

a) "Violência urbana" é a categoria central de uma linguagem constitutiva do senso comum e, portanto, é parte indissociável das atividades a que se refere. Não faz sentido discutir se se trata ou não de uma realidade factual (há quem afirme não passar de uma ficção criada pela mídia), 
embora - da mesma maneira que qualquer outro fenômeno - ela possa ser criticada em suas consequências, como farei adiante tomando o caso do Rio de Janeiro como objeto.

b) Pelo fato de constituir-se como dispositivo central de uma linguagem, a "violência urbana" articula, segundo uma gramática própria, uma série de enunciados - relatos, interpretações, sugestões, avaliações, etc. - que expressam um debate a respeito de um amplo conjunto de práticas ilícitas, as quais, dependendo dos contextos, podem envolver desde a simples incivilidade até a extrema crueldade, passando por variáveis graus de violência física.

c) É claro que as ilicitudes remetem às figuras jurídicas do crime. Porém, embora constituam elementos importantes, não são propriamente elas que articulam o entendimento destas atividades. As condutas de referência são recortadas, apreendidas e sintetizadas pelo efeito, comum a todas, de afetar a continuidade das rotinas diárias (continuidade que ao mesmo tempo expressa e garante os sentimentos básicos de segurança pessoal; Giddens 1991), na medida em que são percebidas como ameaças à integridade física e/ou patrimonial individual. Em suma, a linguagem da "violência urbana" integra e confere sentido às práticas a que se refere a partir da concentração do foco nas atividades rotineiras e nas interações interpessoais. Assaltos, roubos, sequestros, tráfico de drogas, conflitos entre bandos de criminosos, etc., constituem uma ampla e variada nebulosa de condutas - nenhuma das quais representa, isoladamente, uma novidade - que adquirem sentido a partir do enquadramento operado através da linguagem da "violência urbana".

d) O caráter aberto, heterogêneo e poroso da "violência urbana", de um lado, permite uma espécie de circulação, inclusive internacional, das ideias sobre ela (das orientações cognitivas, das avaliações morais e dos sentimentos que lhes são associados, o medo e a insegurança pessoal) e, de outro, implica amplas variações em seus repertórios nacionais e locais, em sua construção histórica, nas particularidades dos debates e nas suas consequências concretas. Em outras palavras, embora tenha se convertido em uma "província" (Schutz) praticamente universal da linguagem de senso comum, em sua concretude a "violência urbana" tem histórias locais, sentido e consequências variadas. Desse modo, a linguagem da "violência urbana" se constitui como conjunto fragmentado de discursos, com distintas origens e conteúdos, cerzidos por uma preocupação comum que combina diferentes níveis de violência física com a identificação (percepções, expectativas e antecipações) de ameaças à continuidade das rotinas diárias. $\mathrm{O}$ foco nas rotinas cotidianas e, portanto, nos aspectos imediatos das interações sociais é um elemento crucial da lógica impregnada na linguagem da "violência urbana". 
e) Estas variações assentam, em grande parte, na formação dos critérios de classificação que definem quais práticas concretas correspondem ao núcleo da "violência urbana" como ameaça à continuidade das rotinas estabelecidas, quais as características típicas de seus agentes e quais os seus níveis de organização. Não há homogeneidade nem estabilidade espaçotemporal nesta classificação, que é sempre contingente (mas não aleatória). A linguagem da "violência urbana", portanto, tem diferentes "histórias internas" que se explicam a si mesmas, daí seu caráter polissêmico e suas ambiguidades. ${ }^{4}$

f) Não obstante sua heterogeneidade, a linguagem da "violência urbana" tematiza processos de desconcentração/reconcentração da violência física. ${ }^{5}$ Aborda os problemas de controle social com a atenção restrita aos riscos de quebra da continuidade das rotinas cotidianas que afetam os sentimentos de segurança individual, como já foi dito. Em consequência, as questões relativas à ordem pública que organiza as interações interpessoais, em seus aspectos mais imediatos, dominam os termos do debate, sobretudo no que diz respeito às necessidades de repressão.

g) Denomino as práticas articuladas pela linguagem da "violência urbana" de sociabilidade violenta. ${ }^{6}$ A característica central delas é a transformação da força física (e suas extensões materiais), de meio de obtenção de interesses, em princípio de coordenação das ações. Na medida em que o reconhecimento coletivo da violência privada dá-se a partir da representação (leiga) de crime, pode-se dizer que a sociabilidade violenta implica uma mudança na organização interna e no sentido das atividades criminais.

h) É o reconhecimento desta mudança que está na base da linguagem da “violência urbana". Ela identifica a constituição, ligada à violência criminal, de uma forma de vida autônoma, com um ordenamento correspondente das condutas, não mais referido à institucionalidade dominante. A sociabilidade violenta, portanto, é um enclave, e pode ser descrita como uma espécie de arcaísmo pós-moderno. Arcaísmo, na medida em que seu

4 Especificamente sobre a história recente da constituição da linguagem da "violência urbana" no Rio de Janeiro, ver Hollanda (2005) e Machado da Silva, Leite e Fridman (2005).

5 Uso com cautela o termo "desconcentração", que merece mais atenção do que posso the conferir aqui. Resumidamente, embora seja evidente que estou pensando no tipo ideal weberiano de monopólio da violência legítima pelo Estado, é relevante reiterar que o trato exatamente como tipo ideal, sem reificá-lo. Assim, "desconcentração" não pressupõe: a) que em algum momento ou lugar o monopólio seja completo e inquestionado, ou que a violência política esgote todas as modalidades de violência física; b) que ela configure situações de dualidade de poder, com a polarização de relações de força entre dois atores coletivos que visariam o controle dos aparelhos de Estado; c) que ela caracterize uma completa pulverização do acesso/uso de meios violentos para a obtenção de fins ideais ou materiais.

6 Tenho escrito vários trabalhos a respeito da sociabilidade violenta. Para não cansar o leitor, indico apenas o mais recente, Machado da Silva (2008b). 
mundo é homogêneo: nele, dissolve-se a diferenciação entre as dimensões econômica, social e cultural. Pós-moderno, porque a inexistência de fronteiras entre esferas de sentido não é provida pelo mito, mas pela (quase) completa dessacralização e reificação que a força, tornada um princípio de coordenação das ações, representa. ${ }^{7}$ Do ponto de vista de sua organização, a sociabilidade violenta é uma ordem empírica governada por uma racionalidade estritamente instrumental que não distingue o mundo social do natural (e, neste sentido, pode ser apresentada como uma espécie de paraíso da "lógica da ação racional").

i) A sociabilidade violenta se produz e reproduz através das atividades de atores competentes, conhecedores ativos, críticos e estratégicos, dessa forma de vida, que se conduzem de uma forma adequada. Entretanto, se eles podem ser conceptualizados como sujeitos, na acepção plena desta palavra, é um problema em aberto. Wieviorka (2005), por exemplo, denomina de antissujeito um tipo social não exatamente idêntico, mas próximo aos atores da sociabilidade violenta. O prefixo, porém, me parece canhestro e um tanto etnocêntrico, pois, no caso aqui tratado, aplica-se a atores que, a rigor, não são "anti" nada; somos nós, que operamos na linguagem da "violência urbana", que nos posicionamos contra sua forma de vida, não importa se com ou sem razão.

j) A capacidade de agregação da sociabilidade violenta é limitada; porém, mesmo assim ela tem sido capaz de se reproduzir e, na medida em que representa o significado da "violência urbana", tem um enorme impacte indireto. No Rio de Janeiro, seus "portadores" típicos são os bandos de traficantes que operam o varejo de drogas em pontos fixos (as "bocas"), ${ }^{8}$ em geral localizados nas favelas e demais territórios da pobreza, provavelmente devido à facilidade logística proporcionada pela modalidade de presença das instituições estatais nessas localidades.

k) As "bocas" precisam ser garantidas ao mesmo tempo contra os competidores e a ação da polícia, o que implica a necessidade de defesa armada. Sobrepõem-se, dessa maneira, o tráfico internacional de drogas, o contrabando de armamentos e as facilidades logísticas decorrentes das deformações da presença das instituições estatais nas periferias urbanas. Estas são as condições de possibilidade (não propriamente causas) da

7 Não creio que os óbvios sobretons hobbesianos ajudem a compreensão dos problemas aqui tratados. A sociabilidade violenta é um enclave e não um mito de origem, até porque se encontra dentro do Leviatã, e a guerra, mesmo que possa ter deixado de ser uma metáfora para transformar-se em modelo de política pública, não dá conta da positividade, ou efetividade, do padrão de relações sociais constitutivo da sociabilidade violenta.

8 Esclarecedor trabalho sobre as diferenças sociais, e suas implicações, entre o comércio de drogas em pontos fixos e o comércio "ambulante" encontra-se em Grillo (2008). Ver também Barbosa (1998). 
sociabilidade violenta. Em torno de seu núcleo duro, gravita toda uma nebulosa de atores e condutas, cuja análise - que não pode ser sequer tentada no espaço deste artigo - deveria orientar-se a partir da descrição das etapas e modalidades de um processo de socialização, conceito mais adequado para compreender a imersão em uma forma de vida do que o de carreira, pois a sociabilidade violenta é muito mais que o horizonte de uma trajetória ocupacional.

1) Acabo de apresentar uma minidescrição sociológica da sociabilidade violenta, tornada necessária para uma compreensão adequada da "violência urbana". Como deve ter ficado claro, minha hipótese é que a linguagem da "violência urbana" apreende e organiza simbolicamente a transformação de parte da violência criminal em uma forma de vida singular, um mundo capaz de se reproduzir de maneira autônoma. Assim, o par "violência urbana"/sociabilidade violenta constitui uma unidade indissociável. Proponho que ele organiza simbólica e praticamente um amplo setor da vida social e tem significativo impacte sobre a sociabilidade, no Rio de Janeiro e, provavelmente, nas grandes cidades brasileiras.

Tudo o que foi dito até aqui implica a necessidade de um comentário específico sobre a atividade policial. Faço-o na próxima seção. Antecipo, porém, que meu objetivo não é propriamente avaliar a polícia (sua organização jurídico-administrativa, seus procedimentos institucionais, sua eficiência, etc.). Meu objetivo é refletir sobre seu lugar no sistema institucional em relação com a linguagem da "violência urbana".

\section{SOBRE A POLÍCIA}

Como sugeri na seção anterior, na linguagem da "violência urbana" a questão da segurança e da ordem pública tem sido compreendida e avaliada de forma cada vez mais limitada à preservação da continuidade das rotinas pessoais. Decorre daí que não é propriamente a questão da regulação das relações entre pessoas, grupos e categorias sociais que fundamenta as expectativas de controle social. Antes, o que está em causa é a demanda pelo bloqueio dessas relações. Segurança pessoal e confinamento (forçado, no caso dos moradores dos territórios da pobreza, ou desejado, no das camadas mais abastadas da população), ou seja, repressão, evitação e afastamento puro e simples, tendem a tornar-se sinônimos.

É óbvio que, neste quadro, a atividade policial e seu papel no exercício das "garantias externas" da ordem social (isto é, da preservação das rotinas), para usar a expressão de Weber, assumem um lugar central na discussão pública. Através dos debates que aí se travam, o reconhecimento cognitivo do enclave constituído pela sociabilidade violenta é moralmente avaliado por seu potencial 
disruptivo, de modo que o foco da atenção é redirecionado para a eficácia da repressão policial. ${ }^{9}$

Creio que a hipótese geral do reconhecimento de um enclave pelo senso comum (um Outro cuja forma de vida não é percebida como inteiramente "humana") - constituído pela sociabilidade violenta ou por outra forma de vida - vale para cidades do mundo inteiro. Contudo, limito-me a explorá-la no caso específico do Rio de Janeiro atual. Nesta cidade, a interpretação coletiva da experiência da ameaça às rotinas cotidianas que fundamenta fortes sentimentos de medo e insegurança levou à "metáfora da guerra” (Leite 2001), seguiu uma trajetória relativamente longa e terminou por concretizar-se, transformada explicitamente em fundamento da política pública de segurança no atual governo estadual, apoiada pelo governo municipal. Por menos representativo que se possa considerar o processo eleitoral no Brasil de hoje, é indubitável que uma linha oficial de atuação conta com o aval de uma ampla parcela da população da cidade.

Não obstante a "guerra aos criminosos" que esta orientação põe a cargo das polícias nada ter a ver com questões de soberania nacional ou guerra civil, ${ }^{10}$ é evidente que ela expressa uma mudança ponderável no conteúdo e no significado histórico atribuídos às "classes perigosas" e, como consequência, no papel da atividade policial. No limite, a discussão pública passa a tratar a polícia como um exército (Brodeur 2004), diferenciando "civis" e "militares": estes cuidam da guerra ao "inimigo", protegendo os afazeres "normais" dos primeiros. Claro está que este arranjo depende de acontecimentos que confirmem o bom andamento da "guerra". Como os acontecimentos demonstram que raramente é o caso, os "civis" passam a criticar a eficiência e a moral dos "militares" e surgem esforços para aperfeiçoar a "máquina de guerra". Esta é a variante hard das propostas de "refundação" da polícia, voltada para o aperfeiçoamento técnico e a elevação do moral dos policiais, de modo a tornar mais eficaz a atividade repressiva. A variante soft enfatiza o retorno à supervisão jurídico-política, que seria a consequência benéfica da intervenção sobre estas mesmas dimensões. Como tratam das mesmas questões e propõem mudanças internas às instituições, há bastante superposição entre as duas variantes.

9 Dessa maneira, mantém-se a presença da sociabilidade violenta como o núcleo empírico do entendimento do problema. No entanto, como a discussão se volta para dentro da própria ordem social que se reconhece ameaçada, a referência de base retorna distorcida como uma espécie de fantasma, ou espectro. Creio ser este o movimento que pode explicar o processo contemporâneo de criminalização da pobreza (a forma atual das "classes perigosas"), pois, na medida em que os "portadores" da sociabilidade violenta tendem a se localizar nas periferias urbanas, a perda de foco representada pelo deslocamento da atenção pública para a atividade policial leva à generalização do "perigo" para toda a população moradora desses territórios.

10 Vale recordar que há uma ampla literatura internacional que procura ampliar a ideia de guerra, como conceito - as "novas guerras" -, para analisar inúmeras formas de violência não política. Esta é, evidentemente, uma perspectiva incompatível com a adotada no presente artigo. 
De todo modo, embora não haja espaço para detalhar esta diferença e suas implicações, não se pode desconsiderar o fato de que a questão da democracia é elemento fundamental na compreensão do que seja "civilizar" a polícia na segunda variante, e está praticamente ausente na primeira.

Mais do que detalhar a estrutura lógica acima delineada - no Rio de Janeiro há massiva evidência dela -, aqui interessa explicitar a ambiguidade dessa compreensão coletiva no que diz respeito às instituições policiais. Por um lado, sua atribuição de mantenedoras da ordem pública converte-se em uma atividade quase patriótica, acompanhada com imensa esperança; por outro lado, como as expectativas são sistematicamente frustradas, a avaliação da atividade policial é sempre negativa, gerando forte desprezo por ela. Mas o que importa sublinhar é o elemento subjacente que cria este aparente paradoxo - a delegação nas instituições policiais da garantia da ordem pública a qualquer preço, já que se trata de uma guerra e já que esta não é uma atividade que deva ser monitorada por civis nem regulada pelos valores vigentes em tempos de paz.

Neste sentido, talvez o principal resultado da compreensão da sociabilidade violenta pela linguagem da "violência urbana" seja a abertura de um amplo espaço para que as corporações policiais decidam, com autonomia e praticamente nenhuma supervisão jurídica ou política, como deve ser exercida sua função social de garantia da ordem pública. A opinião dominante (isto é, o senso comum) apenas espera que a polícia interprete corretamente suas expectativas quanto à continuidade das rotinas e sua noção quanto à natureza das ameaças identificadas e aos atores por elas responsáveis.

Neste quadro de referência, a polícia - e não o debate publicamente regulado entre distintos interesses coletivos - se torna o verdadeiro árbitro do conflito social. Entretanto, dela não se pede moderação ou equidistância, nem tampouco ela é um aparelho vazio, do qual um dos opositores possa apoderar-se. Ao contrário, a delegação que recebe a converte em um ator social, com liberdade para definir e perseguir seus próprios interesses particulares e sua visão de mundo.

É fora de dúvida que isso tem resultado em corrupção e violência (Misse 1997), tão generalizadas que quase podem ser consideradas constitutivas da própria atuação prática da instituição. Entretanto, minha hipótese é que este não é um problema relativo ao funcionamento interno da Polícia Militar, da Polícia Civil ou de qualquer outro aparato repressivo, como se costuma pensar. É fato que estas corporações estão cada vez mais autonomizadas, orientando sua atuação de forma independente, segundo os conflitos entre suas diversas cliques internas, que, por sua vez, seguem interesses e um ethos próprio. Entretanto, é necessário reconhecer que este estado de coisas é consequência do modo pelo qual se processa o debate público em torno dos padrões desejados de organização das relações sociais. Isto significa que a baixa eficácia da prática policial no que diz respeito ao controle do crime violento não pode ser revertida 
apenas pela via de intervenções técnico-administrativas localizadas. Em outras palavras, a linguagem da "violência urbana" não logra propor saídas viáveis para os dilemas que identifica. Dessa maneira, o enclave da sociabilidade violenta, transformado em uma espécie de espectro por uma avaliação moral que lhe é exterior, afeta indiretamente uma discussão na qual seus agentes não participam e pela qual não têm o menor interesse. É o reducionismo essencial da linguagem da "violência urbana", com seu foco nas rotinas cotidianas e sua delegação do controle social - entendido na chave exclusiva da repressão - na polícia, que explica a inviabilidade dos programas de recomposição do tecido social nela baseadas.

O resultado líquido deste processo é que as várias propostas de "reforma intelectual e moral" em curso tenderão a ser absorvidas e neutralizadas (como tem sido o caso até o presente momento) pela atividade prática dos policiais, enquanto não estiverem sustentadas pela adesão ativa do conjunto da sociedade, adesão que, por sua vez, depende do abandono ou, no mínimo, de uma drástica modificação da linguagem da "violência urbana". Ou seja, somente uma linguagem que aborde de forma ampla o tópico do controle social poderá encaminhar intervenções que visem uma recomposição da sociabilidade urbana. Em suma, no lugar de uma reforma intelectual e moral da polícia, dever-se-ia propor uma reforma intelectual e moral da sociedade.

Devo esclarecer que estou longe de advogar o imobilismo diante da gravidade dos problemas. Apenas chamo a atenção contra o que me parece reducionismo e excesso de voluntarismo da perspectiva crítica dominante e aponto para a necessidade de ampliação da análise que deveria servir de base para as propostas de intervenção sobre a prática policial - inclusive ampliação do horizonte temporal, pois não creio que elas devam orientar-se pelo curto prazo. Minha intenção não é desqualificar a reflexão contemporânea sobre as profundas reformas que precisam ser realizadas para tornar eficiente e democrático o funcionamento dos aparelhos policiais e, por extensão, de todo o sistema de administração da justiça. Ela é relevante e se debruça sobre prementes questões reais. Meu comentário é de outra natureza: diz respeito à inviabilidade destes programas de reforma institucional na ausência de um maciço engajamento social que me parece improvável no curto prazo, e cuja necessidade tem sido abafada pela ênfase na dimensão técnico-administrativa e/ou jurídico-formal. ${ }^{11}$

I 1 No momento em que terminei de redigir este artigo, o governo federal estimulava ampla consulta pública por todo o Brasil para recolher sugestões e críticas ao programa nacional de segurança pública que pretende propor (lembro que boa parte dele - o controle do crime comum, por exemplo - terá que ser implementada pelos governos estaduais até que ocorra uma eventual mudança constitucional. É cedo para comentar esta iniciativa, ainda em seus primeiros momentos, porém uma mobilização como esta, mesmo que por inspiração governamental, pode ser o início de uma reversão das tendências que venho analisando. 
Este não é o local para uma crítica detalhada das propostas, algumas das quais são intelectualmente sofisticadas, além de ética e empiricamente bem fundamentadas. No entanto, apesar do risco de simplismo, é relevante para meu argumento apresentar um curto esquema dos principais pontos do raciocínio subjacente a elas:

a) Nas últimas décadas a exacerbação do crime violento tem posto em cheque o desempenho do conjunto das instituições que compõem o sistema de administração da justiça, especialmente as diretamente responsáveis pela manutenção da ordem pública.

b) O aumento da criminalidade resulta da progressiva deterioração - material, técnica e moral - das condições de atuação dos policiais. É, portanto, o baixo custo de oportunidade que explica a difusão dessa atividade desviante que é o crime.

c) Logo, melhorias nas condições institucionais de funcionamento da polícia farão o crime retornar a dimensões "normais". ${ }^{12}$ (A partir deste ponto, as diferentes propostas se dividem quanto à ênfase sobre cada uma das dimensões.)

Minha hipótese é que este raciocínio, na aparência ajustado à realidade e perfeitamente plausível, esquece que a prática policial, ao menos no Brasil urbano, é pré-moderna. As polícias talvez sejam as únicas instituições brasileiras que não se modernizaram. ${ }^{13}$ Não é adequado procurar a explicação para isso em sua história interna, ela deve ser buscada no papel da instituição policial como parte integrante do conflito social.

Nesta linha, procuro a seguir esquematizar porque afirmo que a polícia brasileira é uma instituição pré-moderna.

Recordo, para começar, algumas ideias de Max Weber relativas à produção e distribuição do conhecimento nas burocracias modernas. É certo que o conhecimento operado por qualquer burocracia não é universal, pois se restringe a seus membros - burocratas são portadores de saberes específicos e, reciprocamente, são estes que os definem como burocratas. O que singulariza as burocracias modernas é que, nelas, o conhecimento deixa de ser pessoal, encarnado nos próprios membros das organizações. Através de um longo processo de racionalização ele é expropriado, formalizado e separado dos funcionários-burocratas que o aplicam sem tomá-lo como parte de seus interesses

12 Em outro local, lembrei a proximidade entre a estrutura lógica das propostas e o modelo teórico durkheimiano (Machado da Silva 2004).

13 Esta hipótese, que esquematizo em seguida, ajuda a compreender a convivência da linguagem da "violência urbana" com o processo recente de redemocratização que culminou com a promulgação da "Constituição Cidadã". Toda a luta contra a ditadura, não custa lembrar, se desenrolou no quadro da linguagem dos direitos. 
privados. Esta dissociação pode ser considerada o núcleo cognitivo e moral da fria impessoalidade que Weber considerava típica das burocracias modernas, já que os membros não estão (ou não deveriam estar) pessoalmente envolvidos em suas atividades profissionais. Uma vez que a distribuição do conhecimento é segmentada e formalizada como um sistema de regras impessoais de conduta, os membros das modernas burocracias precisam aprender formalmente esses conhecimentos, que continuam "secretos" no sentido de que não estão universalmente disponíveis (ou seja, de que são "profissionais") e devem operá-los de forma independente de seus interesses pessoais.

Claro está que se trata de referências típico-ideais, as quais, por definição, jamais se encontram em sua pureza na realidade concreta. Este é justamente o ponto que desejo sublinhar. Considero que há evidências suficientes para enfatizar a enorme distância entre o funcionamento das instituições policiais no Brasil e o modelo típico-ideal de burocracia moderna. E, adicionalmente, para afirmar que os programas de intervenção não têm reconhecido esta discrepância. O ponto de partida implícito destes programas é o pressuposto de que nossa polícia é uma burocracia moderna, "apenas" com problemas de funcionamento maiores do que as demais organizações que compõem o sistema institucional brasileiro.

Minha hipótese é outra. Sustentados pela secular delegação que recebem para operar a função repressiva de controle social com ampla liberdade de ação, o conhecimento profissional dos policiais permanece pessoalmente apropriado por eles, como uma posse individual dos agentes, que administram informalmente sua reprodução e transmissão (Nascimento 2008). A definição do que é "ser policial" e de como atuar é produzida pelos próprios membros, segundo seus interesses e orientações práticas e sua interpretação particular sobre as expectativas sociais a respeito do desempenho da função que lhes cabe. Desse modo, as corporações produzem uma cultura própria, autônoma e pouco racionalizada, que depende em grande medida das decisões e trajetórias pessoais de cada policial e dos conflitos internos entre seus diferentes grupos.

Não creio que esse quadro simplesmente resuma os desvios naturais de uma burocracia moderna. Ao contrário, trata-se de um padrão secular que caracteriza a polícia brasileira como uma burocracia pré-moderna, o que é decisivo na forma de organização do conflito social em nosso país. Até o presente momento, esta configuração tem funcionado como uma barreira intransponível para os programas que pretendem reorganizar a prática policial através de uma interferência de natureza técnico-administrativa, pois eles não se adequam à situação real que se propõem modificar.

Este é um aspecto paradoxal do processo de modernização democrática vivido atualmente nas cidades brasileiras. Os avanços em várias dimensões de nossa estrutura institucional - medidas de redução das desigualdades econômicas, integração política, expansão da esfera pública e aumento da transparência 
institucional, etc. - são conhecidos e dispensam exemplos. Ao mesmo tempo, e com velocidade alarmante, a violência física, policial e criminal, se multiplica.

Mais como especulação inicial do que como hipótese explicativa, talvez seja o caso de desfazer esta antinomia sugerindo que a violência física é um elemento fundante de nossa formação social e, por isso mesmo, pouco reconhecido e apenas indiretamente combatido. Mais do que reduzida com o aprofundamento de nossa integração sociocultural e político-econômica, ela tem sido a condição subjacente a este processo, responsável pela prática de uma sociabilidade sempre baseada na segregação, que depende da desqualificação simbólica e do confinamento físico (pela força) do Outro, ainda que a definição de quem deve estar à margem seja variável no tempo e no espaço.

Para concluir o raciocínio, permito-me recorrer a Wieviorka (2005). Este autor, comentando as mais importantes perspectivas de análise da violência, argumenta que "violência" e "conflito" se opõem frontalmente, uma vez que a primeira interrompe a continuidade do conflito (ainda que este possa eventualmente utilizar-se de meios violentos) e, assim, impede o desenvolvimento da sociabilidade. (Deixemos de lado a discussão de certas implicações do argumento de Wieviorka, como, por exemplo, a questão da medida em que a violência é um aspecto contingente, fugaz e descontínuo, incapaz de fundamentar relações sociais de longo prazo - ponto com o qual, obviamente, não concordo -, para tratar de outra questão que me parece central do ponto de vista deste ensaio.)

Wieviorka expressa em seu livro a experiência histórica europeia, particularmente a da constituição da República francesa. O modelo que desenvolve é relevante para a compreensão dos problemas aqui tratados, porém como um modelo contrafactual. No caso brasileiro, a violência policial tem se mostrado uma condição de possibilidade do que aquele autor denomina de "conflito" a luta pacífica, isto é, intersubjetivamente regulada, de valores - e, portanto, a um só tempo, nem se lhe opõe como alternativa nem pode ser identificada com ele. No Brasil, o desenvolvimento do processo de integração social sempre dependeu do alijamento de algum grupo ou categoria, obtido e mantido pela violência física. O principal dispositivo que opera esta conciliação estrutural (violência + conflito) tem sido a reprodução dos aparelhos repressivos como burocracias pré-modernas que garantem o isolamento do Outro. Essa composição tem permitido um significativo - porém sempre limitado - desenvolvimento do processo de modernização institucional.

Até o passado recente, os grupos postos à margem, baseados na expectativa de uma integração futura, sempre reconheceram esta condição (sem que a tenham aceitado plenamente), de modo que estiveram engajados no próprio sistema híbrido que os segregava. Este parece-me o segredo de nossa integração urbana e, talvez mesmo, nacional. A novidade das últimas décadas é que 
um pequeno segmento deste contingente (os "portadores" da sociabilidade violenta) tem assumido positiva e ativamente a condição estrutural que lhe é imposta. (Isto significa que eles não podem mais ser definidos como "sujeitos", no sentido de "assujeitados", produtos do discurso de poder que os define sob o estatuto de criminosos.) Em consequência, à violência policial tradicional adiciona-se, como um enclave (uma forma de vida), a organização autônoma da violência criminal, que denomino de sociabilidade violenta.

Considero desnecessário sublinhar que não estou insinuando nenhum potencial revolucionário relacionado à sociabilidade violenta. Sua constituição não cancela a proposta de Wieviorka de oposição entre "violência" e "conflito", apenas obriga a reconhecer a positividade e efetividade do primeiro destes polos, como princípio de um padrão de sociabilidade capaz de se reproduzir. Revoluções, qualquer seja o entendimento do termo, são da ordem do "conflito", mesmo nos momentos fugazes em que recorrem à "violência". A sociabilidade violenta evolui como um enclave, de modo que não tem capacidade de transformar seu contexto e dissolver-se, e não pode ser assimilada à noção weberiana de luta de valores.

\section{OBSERVAÇÃO FINAL}

Para terminar, gostaria de explicitar uma hipótese que permaneceu implícita ao longo de todo o artigo. Trata-se de sugerir que a linguagem da "violência urbana" transforma profundamente a tematização sobre os problemas gerais de controle social. Tradicionalmente, este tem sido objeto de intenso debate público - inscrito na chave do "conflito", para continuar com Wieviorka tendo por horizonte a questão da revolução. Neste quadro, o controle social é entendido como parte da organização global da sociabilidade, mais precisamente como o elemento responsável pela permanência ou mudança da estrutura social. Não é, portanto, uma função de uma ou outra organização, mas uma atribuição do conjunto do sistema institucional. Assim, nesta chave o que está em questão é a reprodução ou mudança do sistema de dominação, de modo que controle social e controle político terminam por quase se identificar, e o tema das rotinas cotidianas aparece apenas como uma sombra, espécie de consequência secundária, mero epifenômeno. Não vem ao caso discutir a trajetória secular deste debate; aqui, basta indicar que as variações na autorrepresentação da luta de classes desembocaram, no século XX, na linguagem dos direitos, que tem organizado a luta social pacífica mesmo quando eventualmente ocorre o recurso à violência.

O par "violência urbana"/sociabilidade violenta discutido neste artigo alterou radicalmente a tematização do controle social. A linguagem dos direitos não desaparece, mas disputa espaço no debate público com a "violência urbana", que introduz o tópico da continuidade das rotinas cotidianas como um objeto 
urgente de atenção, afetando a autoimagem dos atores sociais, reduzida pela compreensão da sociabilidade ao nível das interações interpessoais. No limite, rompe-se a relação nós-eles garantida pela representação de classes sociais em conflito, transformando a alteridade em uma diferença incomensurável (e intransponível) entre "humanos" e "sub-humanos" ou "bárbaros".

Em suma, proponho que a recomposição do tecido social indiretamente esgarçado pela constituição da sociabilidade violenta depende de uma auto-"refundação" da sociedade.

\section{BIBLIOGRAFIA}

BARbOSA, Antonio Carlos Rafael, 1998, Um Abraço para Todos os Amigos. Niterói, EDUFF.

BRODEUR, Jean-Paul, 2004, "Por uma sociologia da força pública: considerações sobre a força policial e militar", Caderno CRH, XVII (42), 481-489.

FUKS, Mario, 1997, Arenas de Ação e Debate Públicos: Os Conflitos Ambientais e a Emergência do Meio Ambiente enquanto Problema Social no Rio de Janeiro (1985-1992). Rio de Janeiro, IUPERJ/UCAM, tese de doutorado.

GIDDENS, Anthony, 1991, As Consequências da Modernidade. São Paulo, UNESP.

GRILlo, Carolina Christoph, 2008, Fazendo o Doze na Pista: Um Estudo de Caso do Mercado Ilegal de Drogs na Classe Média. Rio de Janeiro, IFCS/UFRJ, dissertação de mestrado.

HOllandA, Cristina Buarque de, 2005, Polícia e Direitos Humanos: Política de Segurança Pública no Primeiro Governo Brizola. Rio de Janeiro, Revan.

LEITE, Márcia da Silva Pereira, 2001, Para Além da Metáfora da Guerra: Percepções sobre Cidadania, Violência e Paz no Grajaú, Um Bairro Carioca. Rio de Janeiro, IFCS/UFRJ, tese de doutorado.

MACHADO DA SILVA, Luiz Antonio, 2004, "Sociabilidade violenta: por uma interpretação da criminalidade violenta no Brasil urbano", em L.C.Q. Ribeiro (org.), Metrópoles: Entre a Cooperação e o Conflito. São Paulo e Rio de Janeiro, Perseu Abramo/FASE, 291-315 .

- (org.), 2008a, Vida sob Cerco: Violência e Rotina nas Favelas do Rio de Janeiro. Rio de Janeiro, Nova Fronteira/Faperj.

—, 2008b, "Violência urbana, sociabilidade violenta e agenda pública”, em Luiz Antonio Machado da Silva (org.), Vida sob Cerco: Violência e Rotina nas Favelas do Rio de Janeiro. Rio de Janeiro, Nova Fronteira/Faperj, 35-45.

MACHADO DA SILVA, L.A., Márcia P. LEITE, e L. Carlos FRIDMAN, 2005, "Matar, morrer, civilizar: o "problema da segurança pública'”, em MAPAS: Monitoramento Ativo da Participação da Sociedade. Rio de Janeiro, Ibase, 2-34.

MISSE, Michel, 1997, "As ligações perigosas: mercado informal ilegal, narcotráfico e violência no Rio de Janeiro”, Comtemporaneidade e Educação, 2 (1): 93-1 16. 
NASCIMENTO, Andréa Ana do, 2008, A Especialização sem Especialistas: Um Estudo sobre as Práticas (In)formais de Investigação e de Transmissão de Conhecimento nas Delegacias Especializadas. Rio de Janeiro, IFCS/UFRJ, dissertação de mestrado.

SCHUTZ, Alfred, 1964, Collected Papers. Haia: Hayam Martinus Nijhoff, 2 vols.

SOARES, Luiz Eduardo, 2009, "Refundar as polícias", Le Monde Diplomatique Brasil, 6 de janeiro.

WIEVIORKA, Michel, 2005, La Violence. Paris, Hachette Littératures.

Reconstruct police or society? Violence, democracy and public order in contemporary Rio de Janeiro - Luiz Antonio Machado da Silva - Professor titular do IUPERJ/UCAM e professor associado do IFCS/UFRJ, Brasil • machadodasilvaluizantonio@gmail.com

The article starts from the hypothesis that "urban violence" is at the center of a grammar that deals with certain diffuse forms of autonomous social organization of violence perceived as endangering personal and patrimonial integrity. Influenced by such a language, public debate on social regulation and control shrinks to the question of maintaining the public order through avoiding interclass contacts and structural political conflicts. The article suggests that this demand for group and personal isolation imply, as a consequence, delegating police institutions to decide on how, when and who menace the pacific prosecution of everyday activities. Therefore, the generalized public demand for police "reconstruction from the beginning" will not be met if societal approach does not change from the language of "urban violence" back to the democratic language of rights, so that police practices can be object of attention and control. Above all, it is 'society' - an historical modality of social relations - which needs to be 'reconstructed'.

KEYWORDS: Rio de Janeiro, urban violence, drug dealing, public order, sociability, social segregation. 